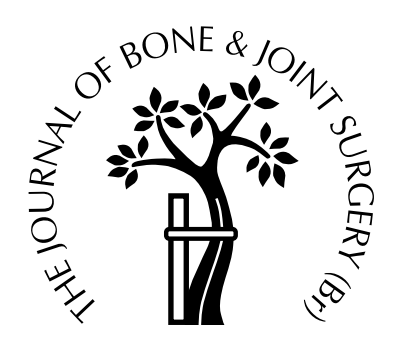

\title{
The use of antibiotic-impregnated cement in infected reconstructions after resection for bone tumours
}

\author{
Davide Donati, Roberto Biscaglia \\ From the Rizzoli Orthopaedic Institute, Bologna, Italy
}

$\mathbf{W}$ e have studied 35 patients with infected reconstructions after segmental resection for bone tumours. Two different regimes of treatment were employed both of which entailed debridement and the use of cement impregnated with antibiotic. In 25 patients gentamicin-PMMA beads were used and in ten an antibiotic-impregnated cement spacer. Better results were achieved with the second procedure in terms of cases healed, the number of operations, time of healing, time of recovery and the functional score. The use of vancomycin in the cement spacer gave better local control.

J Bone Joint Surg [Br] 1998;80-B:1045-50.

Received 24 November 1997; Accepted after revision 3 June 1998

Massive segmental skeletal reconstruction after resection of bone tumours is often followed by complications. ${ }^{1}$ Infection is the major cause of early failure and the most challenging for both surgeon and patient. ${ }^{2,3}$

The essential surgical step in the treatment of chronic osteomyelitis is radical debridement of all infected and necrotic tissue and removal of foreign material. ${ }^{4} \mathrm{~A}$ combination of continuous irrigation and suction is required to remove necrotic tissue. ${ }^{5}$

Local antibiotic therapy using chains of gentamicin polymethylmethacrylate (PMMA) beads is an established technique in septic bone surgery. Buchholz and Engelbrecht ${ }^{6}$ and Buchholz and Gartmann ${ }^{7}$ reported the efficacy of antibiotic-loaded bone cement in the management of infected total hip arthroplasties and this was confirmed in further pharmacokinetic studies by Wahlig and Buchholz. ${ }^{8}$ They reported local levels of antibiotic 200 times higher than those achieved by systemic administration. Walenkamp et $\mathrm{al}^{9}$ showed that the serum and urine concentrations of gentamicin after the implantation of gentamicin PMMA

D. Donati, MD, Assistant Professor

R. Biscaglia, MD, Research Fellow

1st Orthopaedic Clinic, University of Bologna, Rizzoli Orthopaedic Institute, Via Pupilli 1, 40126 Bologna, Italy.

Correspondence should be sent to Dr D. Donati.

(C)1998 British Editorial Society of Bone and Joint Surgery 0301-620X/98/68570\$2.00

VOL. 80-B, No. 6, NOVEMBER 1998 beads were much lower than those after systemic use. The clinical assessment of this method has been validated in post-traumatic, postoperative and haematogenous osteomyelitis and in infected conventional total hip and knee arthroplasty. ${ }^{10-14}$

Since 1981 we have been using gentamicin-PMMA beads in infected reconstructions after resection of bone tumours. Rotation of muscle flaps ${ }^{15-18}$ can be used to heal the infection without removal of the prosthesis. When the prosthetic component is to be removed, however, a twostage procedure has to be considered. ${ }^{19}$ Since 1992 we have used antibiotic-impregnated acrylic cement as a block spacer. This technique has proved to be successful in infected conventional knee and hip prostheses, ${ }^{20-23}$ preserving length and space for later reinsertion of an implant. Our aim in this study was to compare the use of PMMA beads and cement spacers.

\section{Patients and Methods}

There were 35 patients in the study divided into two groups. Group 1 consisted of 25 patients in whom gentamicin-PMMA beads were inserted and group 2 of ten patients who had an antibiotic-impregnated cement spacer. Details of both groups are given in Table I.

Group 1. The 25 patients had a mean age of 20 years (11 to 53). The most commonly affected site was around the knee. The type of tumour was an osteosarcoma in 16 patients, a chondrosarcoma in three, Ewing's sarcoma in two, and an adamantinoma, haemangioendothelioma, malignant fibrous histiocytoma and giant-cell tumour in one each. Postoperative antitumour chemotherapy was given in 16 patients.

After the resection, 12 patients with the tumour localised at the distal femur or the proximal tibia had a non-cemented Howmedica Modular Resection System (HMRS) prosthesis (Howmedica International) inserted (Fig. 1). Three (proximal humerus) had a cemented Modular Resection System prosthesis, one (proximal femur) a cemented IOR modular prosthesis (Officine Orthopediche, Rizzoli, Italy), one (total humerus) a cemented custom-made prosthesis, and in five intercalary or articular resections a cement spacer was fixed by a nail (3), plate (1) or external fixator (1). Autogenous bone was implanted in three patients. 
Table I. Details of the two groups

\begin{tabular}{|c|c|c|}
\hline & Gentamicin beads & Cement spacer \\
\hline Number of cases & 25 & 10 \\
\hline Mean age in years (range) & $20(11$ to 53$)$ & 27 (4 to 70$)$ \\
\hline \multicolumn{3}{|l|}{ Site } \\
\hline Humerus & 4 & 1 \\
\hline Femur & 14 & 6 \\
\hline Tibia & 7 & 3 \\
\hline \multicolumn{3}{|l|}{ Reconstruction } \\
\hline Prosthesis & 16 & 6 \\
\hline Cemented & 5 & - \\
\hline Uncemented & 11 & 6 \\
\hline Grafts & 3 & 3 \\
\hline Temporary spacer & 5 & 1 \\
\hline Postoperative complications & 5 & 3 \\
\hline Risk factors & 6 & 7 \\
\hline Early infections & $15(60 \%)$ & $5(50 \%)$ \\
\hline \multicolumn{3}{|l|}{ Infection signs } \\
\hline Sinus & 14 & 7 \\
\hline Swelling & 3 & 2 \\
\hline Wound slough & 8 & 1 \\
\hline \multicolumn{3}{|l|}{ Bacteria } \\
\hline Coagulase-negative Staphylococcus & $17(70 \%)$ & $6(60 \%)$ \\
\hline Staph. aureus & 9 & 1 \\
\hline Others & - & 3 \\
\hline Negative samples & 1 & - \\
\hline
\end{tabular}

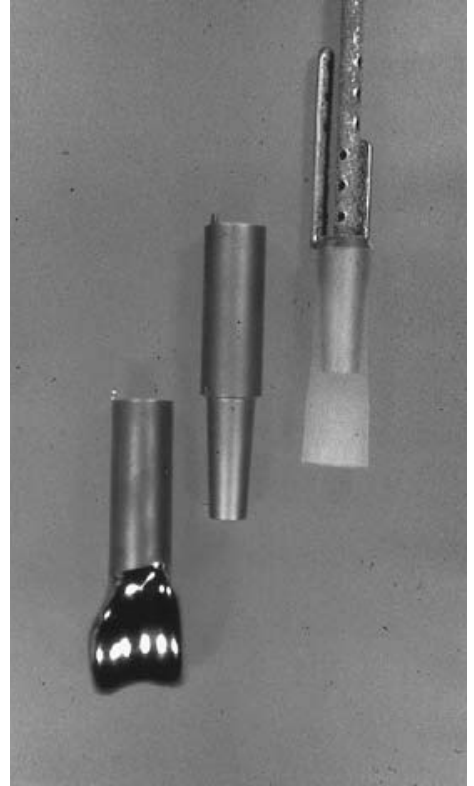

Fig. 1a

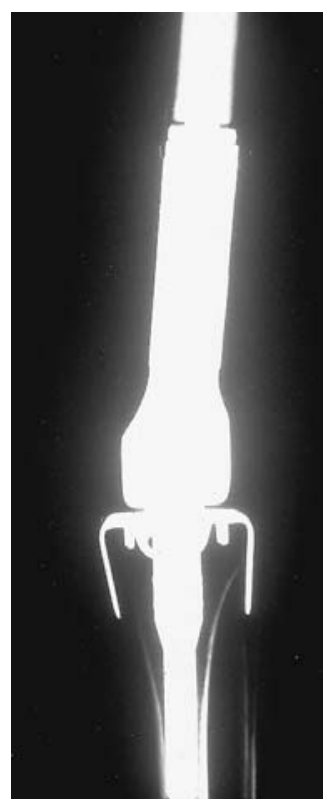

Fig. 1b

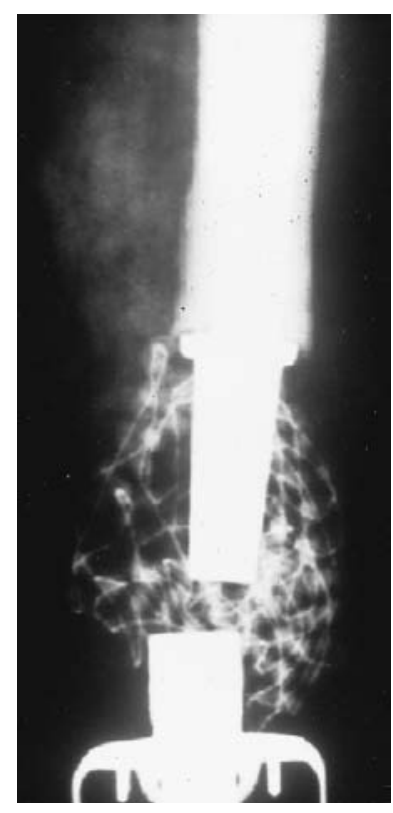

Fig. 1c

Figure 1a - The HMRS non-cemented modular system for reconstruction of the distal femur and proximal tibia. Figures $1 \mathrm{~b}$ and $1 \mathrm{c}-$ Anteroposterior radiographs showing $\mathrm{b}$ ) an implanted HMRS prosthesis in the distal femur and c) with beads in place.

Six patients had additional risk factors: diabetes, a pathological fracture, contemporary thoracotomy for lung metastases, and oral infection in one each and postoperative direct trauma in two. Postoperative complications were seen in five patients: a haematoma in three, persistent fever after surgery in one, and an external popliteal nerve palsy in one.

Infection developed in 15 patients $(60 \%)$ within three months, in 12 immediately after surgery, while in the remaining ten it appeared at a mean of nine months (3 to 61). A draining sinus was detectable in 14 patients and in two was associated with fever. Three patients had local swelling and inflammation, and eight a wound slough. Culture samples grew coagulase-negative Staphylococcus in 17 patients $(68 \%)$, associated with other bacteria in six. In nine Staphylococcus aureus was grown, with other organisms in three. In one case culture samples proved sterile in spite of clinical evidence of infection. 


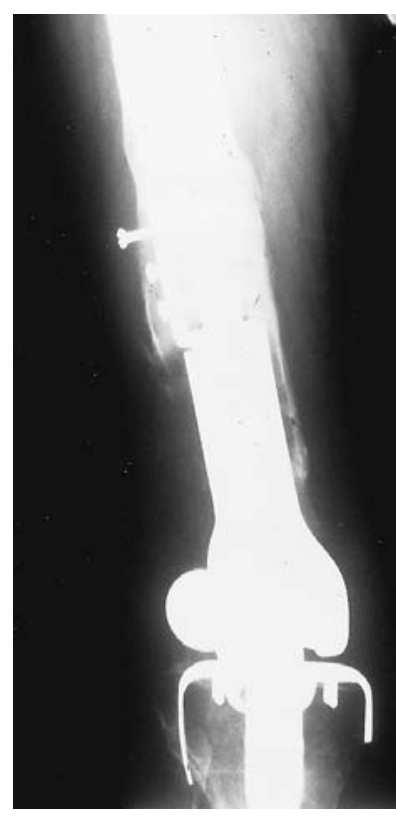

Fig. 2a

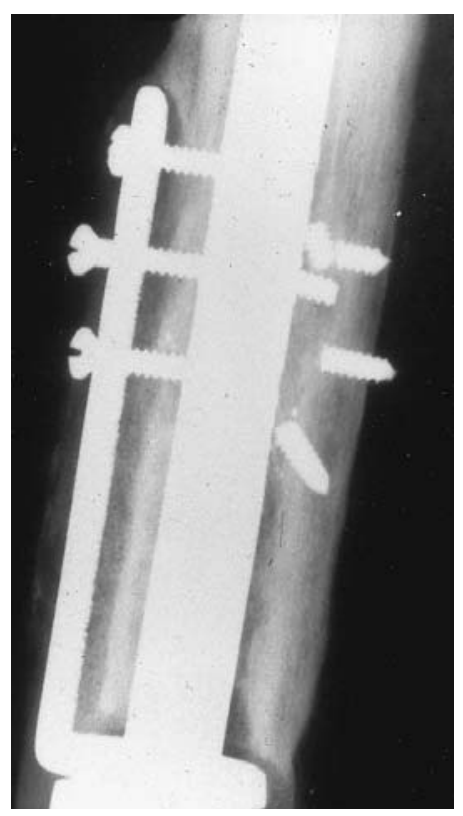

Fig. 2b

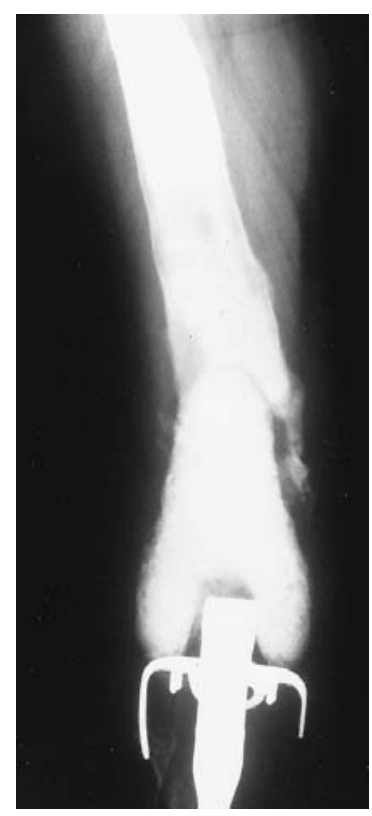

Fig. 2c

Radiographs showing a) infection after reconstruction of the distal femur, b) augmentation of the distal femoral bone with signs of bone involvement and c) the spacer in place; it fractured after four weeks.

In all patients treatment included extensive surgical debridement with intravenous antibiotics for at least five days during the perioperative period. Gentamicin-PMMA beads were inserted using as many chains as possible and were removed or replaced between three and four weeks later. The procedure was repeated several times until no clinical or laboratory signs of infection were present.

Group 2. The mean age of the ten patients was 27 years (4 to 70). The tumour was an osteosarcoma in four, giant-cell tumour in three, Ewing's sarcoma in two and a leiomyosarcoma in one. After operation antitumour chemotherapy was given to seven patients. Reconstruction was performed in six using an HMRS prosthesis (Fig. 2). In three a bone allograft was implanted and an intercalary reconstruction with cement and plates was carried out in one.

Seven patients had one of the following risk factors: diabetes, obesity, pathological fracture, direct trauma after surgery, curettage before resection, patellar tendon reinsertion and osteosynthesis with a plate for fracture around the prosthesis. There were postoperative complications in three patients, with fever immediately after surgery in two and thrombophlebitis in one.

Infection developed in five patients within three months, in one immediately after surgery. In the remaining five it was evident after a mean of ten months (3 to 59). A draining sinus was detectable in seven patients, in one associated with fever, in two with local swelling and inflammation and in one with wound slough. Culture samples grew coagulase-negative Staphylococcus in six patients, in one associated with other bacteria. In three Staphylococcus aureus was grown, in one associated with other organisms. In one patient Escherichia coli was cultured in association with Bacteroides fragilis.
In three patients a spacer was implanted after persistent infection previously treated by local irrigation. In uncemented reconstructions partial or total removal of the implant was always carried out: in two cases only the stems were removed.

As much cement was used as was necessary to fill the whole space left by the retrieved implant. In seven patients the cement was reinforced by a Küntscher nail. Vancomycin was the antibiotic of choice in seven patients, mixed with cement in quantities varying between 3 and $9 \mathrm{~g}$ per cement pack. Cefamandole $(2 \mathrm{~g})$ was used in two and gentamicin $(30 \mathrm{mg})$ in one.

All the patients were followed clinically and radiologically. Laboratory tests included measurement of the ESR, C-reactive protein, WBC, fibrinogen and gamma proteins. We performed functional evaluation according to the MSTS system. $^{24}$

\section{Results}

Group 1. Details are given in Table II. Surgical debridement and bead insertion were the primary treatment in 16 patients, while in nine the initial debridement was followed by continuous lavage. Partial removal of the reconstruction was performed in three patients with autografts. The infection healed in all three, with satisfactory results in two. Because the signs of infection were mild in three patients treatment was performed without removing the implant with bead chains applied around the body of the prosthesis. However, in two, amputation was necessary and the third patient still has a draining sinus and an unsatisfactory functional result. 
In 19 patients in whom the implant was removed, six had the same type of prosthesis reinserted. This was successful in three. Two patients still have infection and one has been lost to follow-up. In five other patients a different reconstruction was performed as a salvage procedure. In four this was successful and one still has infection. Of the remaining patients, four have a flail limb, with one still infected, and four required amputation.

The most constant and significant indicator of infection was the ESR. This returned close to the normal level in most cases after treatment. After a mean interval of 31 months (3 to 83) and between two and eight operative procedures (mean 4.7), the infection settled in 19 patients (76\%), although six required amputation (24\%) and three have a flail limb. In those treated with postoperative chemotherapy the only notable feature was a higher rate of amputation $(31 \%)$. Functional activity recovered at a mean of 25 months ( 3 to 92 ) and in patients in whom the lower limb was affected weight-bearing was achieved at a mean of 38 months (6 to 104). Satisfactory functional results were obtained in five patients $(20 \%)$. The mean follow-up was 96 months (24 to 169).

Group 2. Details are given in Table III. Evidence of infection in most cases was a draining sinus. Removal of the implant was performed in five: two had an allograft, one temporary cement reconstruction and two an HMRS prosthesis. In the remaining patients in whom uncemented components had been used, only the body of the prosthesis could be retrieved. In the composite prosthesis (case 7, Table III) only the allograft was excised and the prosthesis was completely covered by antibiotic-impregnated cement. Three patients required further revision of the prosthesis, in two once, and in

Table II. Results in patients in group 1 (bead chains)

\begin{tabular}{|c|c|c|c|c|c|c|c|c|c|}
\hline Case & $\begin{array}{l}\text { Age } \\
(\mathbf{y r})\end{array}$ & $\begin{array}{l}\text { Type of } \\
\text { reconstruction }\end{array}$ & Site* & $\begin{array}{l}\text { Time to } \\
\text { infection } \\
(\mathrm{mth})\end{array}$ & $\begin{array}{l}\text { Time to } \\
\text { surgery } \\
\text { (mth) }\end{array}$ & $\begin{array}{l}\text { Time } \\
\text { to heal } \\
\text { (mth) }\end{array}$ & $\begin{array}{l}\text { Number of } \\
\text { operations }\end{array}$ & Outcome & $\begin{array}{l}\text { Functional } \\
\text { result }\end{array}$ \\
\hline 1 & 21 & $\mathrm{KRA} † /$ autog & PT & 2 & 0 & 76 & 8 & Partial retrieve & Good \\
\hline 2 & 17 & Prosthesis & $\mathrm{PH}$ & 8 & 0 & 3 & 4 & Loosening & Good \\
\hline 3 & 11 & Cement spacer & DF & 0 & 17 & 13 & 4 & Amputation & Poor \\
\hline 4 & 13 & Prosthesis & PT & 0 & 1 & 7 & 5 & Prosthesis & Fair \\
\hline 5 & 13 & Cement spacer & DF & 1 & 8 & 49 & 4 & Prosthesis & Good \\
\hline 6 & 15 & Prosthesis & PT & 0 & 0 & 28 & 4 & Amputation & Poor \\
\hline 7 & 12 & Prosthesis & PT & 0 & 0 & 61 & 8 & Flail & Poor \\
\hline 8 & 13 & Prosthesis & DF & 1 & 0 & 5 & 8 & Prosthesis & Lost to follow-up \\
\hline 9 & 13 & Prosthesis & $\mathrm{PH}$ & 18 & 2 & 30 & 5 & Flail & Poor \\
\hline 10 & 53 & Prosthesis & DF & 12 & 0 & / & 4 & Prosthesis/sinus & Fair \\
\hline 11 & 13 & Prosthesis & DF & 0 & 0 & 21 & 5 & Prosthesis & Good \\
\hline 12 & 30 & Prosthesis & $\mathrm{PH}$ & 0 & 1 & 5 & 4 & Flail & Poor \\
\hline 13 & 16 & Prosthesis & PT & 0 & 3 & 1 & 3 & Amputation & Poor \\
\hline 14 & 28 & Cement spacer & PT & 1 & 3 & I & 2 & Autograft/nonunion & Poor \\
\hline 15 & 20 & Cement spacer & DF & 3 & 29 & / & 2 & Prosthesis/sinus & Good \\
\hline 16 & 13 & Autograft & SF & 26 & 5 & 11 & 4 & Vascular fibula & Poor \\
\hline 17 & 17 & Autograft & ST & 7 & 0 & 14 & 4 & Partial retrieve & Good \\
\hline 18 & 11 & Cement spacer & DF & 2 & 1 & 4 & 3 & Amputation & Poor \\
\hline 19 & 12 & Prosthesis & DF & 11 & 3 & / & 6 & Prosthesis/sinus & Fair \\
\hline 20 & 27 & Prosthesis & DF & 1 & 0 & 83 & 6 & Amputation & Poor \\
\hline 21 & 15 & Prosthesis & DF & 61 & 0 & 25 & 5 & Amputation & Poor \\
\hline 22 & 30 & Prosthesis & $\mathrm{PH}$ & 20 & 0 & / & 2 & Flail limb/sinus & Poor \\
\hline 23 & 35 & Prosthesis & $\mathrm{PF}$ & 43 & 5 & 81 & 6 & Allograft/nonunion & Fair \\
\hline 24 & 15 & Prosthesis & $\mathrm{PF}$ & 2 & 1 & / & 6 & Prosthesis/sinus & Fair \\
\hline 25 & 31 & Prosthesis & DF & 9 & 1 & 13 & 6 & Vascular fibula & Fair \\
\hline
\end{tabular}

* $\mathrm{P}$, proximal; $\mathrm{D}$, distal; $\mathrm{S}$, diaphysis; $\mathrm{T}$, tibia; $\mathrm{F}$, femur; $\mathrm{H}$, humerus

$\dagger$ Knee resection arthrodesis

Table III. Results in patients in group 2 (spacers)

\begin{tabular}{|c|c|c|c|c|c|c|c|c|c|c|}
\hline Case & $\begin{array}{l}\text { Age } \\
(\mathbf{y r})\end{array}$ & $\begin{array}{l}\text { Type of } \\
\text { reconstr }\end{array}$ & Site* & $\begin{array}{l}\text { Time to } \\
\text { infection } \\
(\mathrm{mth})\end{array}$ & $\begin{array}{l}\text { Time to } \\
\text { surgery } \\
\text { (mth) }\end{array}$ & $\begin{array}{l}\text { Antibiotics } \\
x \text { cem pack } \dagger\end{array}$ & $\begin{array}{l}\text { Time } \\
\text { to heal } \\
\text { (mth) }\end{array}$ & $\begin{array}{l}\text { Number of } \\
\text { operations }\end{array}$ & Outcome & $\begin{array}{l}\text { Functional } \\
\text { result }\end{array}$ \\
\hline 1 & 13 & Allograft & $\mathrm{PH}$ & 3 & 1 & Cef $2 \mathrm{~g}$ & 2 & 2 & Cement spacer & Good \\
\hline 2 & 15 & Prosthesis & DF & 2 & 0 & Vanc $5 \mathrm{~g} /$ vanc $5 \mathrm{~g}$ & 5 & 4 & Prosthesis & Excellent \\
\hline 3 & 4 & Allograft & SF & 0 & 0 & Gent $30 \mathrm{mg}$ & 4 & 4 & Amputation & Poor \\
\hline 4 & 33 & Prosthesis & DF & 59 & 10 & Vanc $9 \mathrm{~g}$ & 7 & 3 & Prosthesis & Good \\
\hline 5 & 53 & Prosthesis & PT & 4 & 0 & Cef $2 \mathrm{~g}$ & 16 & 3 & Amputation & Poor \\
\hline 6 & 70 & Prosthesis & DF & 0 & 0 & Vanc $5 \mathrm{~g}$ & / & 3 & Prosthesis/sinus & Fair \\
\hline 7 & 11 & Allo+ Prost & $\mathrm{PF}$ & 1 & 0 & Vanc $3 \mathrm{~g}$ & 6 & 3 & Cement + prosth & Good \\
\hline 8 & 24 & Prosthesis & PT & 8 & 7 & Vanc $4 \mathrm{~g} / \mathrm{vanc} 4 \mathrm{~g}$ & 14 & 3 & Prosthesis & Fair \\
\hline 9 & 13 & Cem spacer & ST & 6 & 2 & Vanc $5 \mathrm{~g}$ & 2 & 1 & Prosthesis & Fair \\
\hline 10 & 34 & Prosthesis & DF & 22 & 0 & $\begin{array}{l}\text { Vanc } 4 \mathrm{~g} / \text { cef } 4 \mathrm{~g} \\
\text { Cef } 4 \mathrm{~g} / \text { cef } 4 \mathrm{~g}\end{array}$ & 10 & 7 & Prosthesis & Good \\
\hline
\end{tabular}

\footnotetext{
* P, proximal; D, distal; S, diaphysis; T, tibia; F, femur; H, humerus
}

$\dagger$ Cef, cefamandole; Vanc, vancomycin; Gent, gentamicin 
Table IV. Comparison of results with gentamicin beads and cement spacers

\begin{tabular}{lcc}
\hline & Gentamicin beads & Cement spacer \\
\hline Follow-up time (mth; range) & $96(24$ to 169$)$ & 40 (22 to 84$)$ \\
Number of operations (range) & $4(2$ to 8$)$ & $3.3(1$ to 7$)$ \\
Healed cases (\%) & $19(76)$ & $9(90)$ \\
Time to heal (mth; range) & $31(3$ to 86$)$ & 10 (3 to 21) \\
Recovery of functional activity (mth; range) & $25(3$ to 92$)$ & 9 (4 to 22) \\
Weight-bearing (mth; range) & $38(6$ to 104$)$ & $13(5$ to 26$)$ \\
Amputation (\%) & $6(24)$ & $2(20)$ \\
Flail limb (\%) & $4(16)$ & $0(0)$ \\
Satisfactory functional results $(\%)$ & $6(24)$ & $5(50)$ \\
\hline
\end{tabular}

one, three times because of persistent clinical signs of infection. The last patient (case 10) suffered an allergic reaction to vancomycin after insertion of the first spacer.

When the infection seemed to have been overcome, a similar reconstruction was performed in six patients. In two a different procedure was carried out and two required amputation.

After a mean of ten months ( 3 to 21) and between two and seven operations (mean 3.3) infection was overcome in nine patients although two had required amputation. Of those who did not have amputation, vancomycin was used in seven. Satisfactory function was achieved in five patients after a mean interval of nine months (4 to 22) and weightbearing was possible at a mean of 13 months (5 to 26). The mean follow-up was 40 months ( 22 to 84 ). Table IV gives a comparison of the results in both groups.

\section{Discussion}

About $10 \%$ of prostheses which have been implanted after resection of bone tumours become infected. We have improved our results in the management of this problem by early aggressive surgery, with removal of the implant when indicated, and the use of antibiotic-loaded cement spacers.

There is still controversy as to the treatment of suspected deep infection. When the physical signs suggest the presence of pus surgical debridement should be performed immediately, and in $50 \%$ of the cases reported in our previous study ${ }^{16}$ healing occurred after continuous irrigation. When the signs of infection are less clear treatment with antibiotics may be started by an inexperienced physician. This may lead to early suppression of the infection which may later become chronic. Definitive treatment will be delayed and may then be less effective (Table II).

Postoperative chemotherapy is not associated with a higher rate of infection, but a leucopenia may weaken the defence of the body against infection when present. A mild infection may progress rapidly in the presence of cytotoxic agents.

Attempts have been made to grade an infection in order to influence decisions about surgery. The most valuable blood test is the ESR and we have found that the clinical signs are the most reliable. We usually wait for six months after infection has subsided before attempting further reconstructions. Attempts at a one-stage procedure have resulted in a rate of reinfection of up to $30 \% .^{10,21,23,25}$
Cement loaded with antibiotic has proved effective but the choice of antibiotic is uncertain. More than $70 \%$ of the infections are due to either coagulase-negative cocci or Staphylococcus aureus and half are methicillin-resistant. ${ }^{26,27}$ Glycopeptides such as vancomycin and teicoplanin have been shown to be effective against these bacteria. Vancomycin combined with tobramycin is recommended as having a broader action on the CNS compared with gentamicin, and it is less nephrotoxic. ${ }^{28,29}$ Moreover, tobramycin has a better elution characteristic than vancomycin, ${ }^{27}$ and the combination seems to give enhanced elution with more accurate control of infection. ${ }^{28}$ There is evidence, however, that other materials such as biodegradable cement and collagen sponges give more complete and faster delivery of antibiotic. $^{30,31}$

Conclusion. Antibiotic-impregnated cement spacers have been shown to be more effective in the rate and time of healing, frequency of repeated surgery and functional results, as compared with PMMA beads. The treatment of deep infection of large prostheses after resection of bone tumours remains controversial.

In early infection several methods can achieve success in $50 \%$ to $70 \%$ of the cases, while for the remainder or in late infection, the removal of the implant and a high local concentration of antibiotic are needed. The combination of antibiotics and an improved cement or other material is advisable for a better elution and higher and faster concentration of local antibiotics. Reliable and reproducible laboratory and image-based tests are needed to diagnose more accurately the early onset of the infection and to monitor the outcome.

This study was partially supported by grants from the Research Project of CNR, Italy and the Current Research Project IOR, Bologna.

No benefits in any form have been received or will be received from a commercial party related directly or indirectly to the subject of this article.

\section{References}

1. McDonald DJ, Capanna R, Gherlinzoni $\mathbf{F}$, et al. Influence of chemotherapy on perioperative complications in limb salvage surgery for bone tumors. Cancer 1990;65:1509-16.

2. Capanna R, Casadei R, Bettelli G, et al. Infection in limb salvage surgery. J Bone Joint Surg [Br] 1992;74-B:Suppl 1,106.

3. Lord CF, Gebhardt MC, Tomford WW, Mankin HJ. Infection in bone allografts: incidence, nature, and treatment. J Bone Joint Surg [Am] 1988;70-A:369-76.

4. Klemm KW. Antibiotic bead chains. Clin Orthop 1993;295:63-76.

5. Willenegger $\mathbf{H}$. Clinical aspects and therapy of pyogenic bone infections. Chirurg 1970;41:215-21.

6. Buchholz HW, Engelbrecht H. Depot effects of various antibiotics mixed with palacos resins. Chirurg 1970;41:511-5. 
7. Buchholz HW, Gartmann HD. Infection prevention and surgical management of deep insidious infection in total endoprosthesis. Chirurg 1972;43:446-53.

8. Wahlig H, Buchholz HW. Experimental and clinical studies on the release of gentamicin from bone cement. Chirurg 1972;43:441-5.

9. Walenkamp GHIM, Vree TB, Guelen PJM, Jongmann-Nix B. Pharmacokinetic and nephrotoxicologic study to the use of gentamicin-PMMA-beads. Proc 13th Int Congress Chemotherapy, Vienna, 1983;43:20.

10. Nelson CL, Evans RP, Blaha JD, et al. A comparison of gentamicinimpregnated polymethylmethacrylate bead implantation to conventional parenteral antibiotic therapy in infected total hip and knee arthroplasty. Clin Orthop 1993;295:96.

11. Henry SL, Hood GA, Seligson D. Long-term implantation of gentamicin-polymethylmethacrylate antibiotic beads. Clin Orthop 1993; 295:47-53.

12. Evans RP, Nelson CL. Gentamicin-impregnated polymethylmethacrylate beads compared with systemic antibiotic therapy in the treatment of chronic osteomyelitis. Clin Orthop 1993;295:37-42.

13. Blaha JD, Calhoun JH, Nelson CL, et al. Comparison of the clinical efficacy and tolerance of gentamicin PMMA beads on surgical wire versus combined and systemic therapy for osteomyelitis. Clin Orthop 1993;295:8-12.

14. Georgiadis GM, DeSilva SP. Reconstruction of skeletal defects in the forearm after trauma: treatment with cement spacer and delayed cancellous bone grafting. J Trauma 1995;38:910-4.

15. Manfrini M, Capanna R, Caldora P, Gaiani LI. Gastrocnemius flaps in the surgical treatment of sarcomas of the knee. Chir Organi Mov 1993;78:95-104.

16. Donati D, D'Arenzo R, Ercolani C, Boriani S. Infection in limb salvage surgery for bone tumors. Eur J Orthop Surg Traumatol 1995;5:1.

17. Eckardt JJ, Lesavoy MA, Dubrow TJ, Wackym PA. Exposed endoprosthesis: management protocol using muscle and myocutaneous flap coverage. Clin Orthop 1990;251:220-9.

18. Horowitz SM, Lane JM, Otis JC, Healey JH. Prosthetic arthroplasty of the knee after resection of a sarcoma in the proximal end of the tibia: a report of sixteen cases. J Bone Joint Surg [Am] 1991; 73-A:286-93.
19. Peterson SA, Fitzgerald RH. Complications of musculoskeletal infections. In: Epps CH ed, Complications in Orthopaedic Surgery. Vol 1. Philadelphia: J.B. Lippincott 1994;155-82.

20. Gusso MI, Capone A, Civinini R, Scoccianti G. La tecnica del blocco spaziatore nei reinterventi per mobilizzazione settica delle artroprotesi di ginocchio. Chir Org Mov 1995;53:21-7.

21. Scott IR, Stockley I, Getty CJM. Exchange arthroplasty for infected knee replacements: a new two-stage method. J Bone Joint Surg [Br] 1993;75-B:28-31.

22. Hofmann AA, Kane KR, Tkach TK, Plaster RL, Camargo MP. Treatment of infected total knee arthroplasty using an articulating spacer. Clin Orthop 1995;321:45-54.

23. Ivarsson I, Wahlström O, Djerf K, Jacobsson SA. Revision of infected hip replacement: two-stage procedure with a temporary gentamicin spacer. Acta Orthop Scand 1994;65:7-8.

24. Enneking WF, Dunham W, Gebhardt MC, Malawar M, Pritchard DJ. A system for the functional evaluation of reconstructive procedures after surgical treatment of tumours of the musculoskeletal system. Clin Orthop 1993;286:241-6.

25. Lieberman JR, Callaway GH, Salvati EA, Pellicci PM, Brause BD. Treatment of the infected total hip arthroplasty with a two-stage reimplantation protocol. Clin Orthop 1994;301:205-12.

26. Mehtar S. The continuing problem of 'hospital staphylococci': why? J Chemother 1994;6:Suppl4, :25-31.

27. James PJ, Butcher IA, Gardner ER, Hamblen DL. Methicillinresistent Staphylococcus epidermidis in infection of hip arthroplasties. J Bone Joint Surg [Br] 1994;76-B:725-7.

28. Duncan CP, Masri BA. The role of antibiotic-loaded cement in the treatment of an infection after a hip replacement. J Bone Joint Surg [Am] 1994;76-A:1742-51.

29. Tsukayama DT, Estrada R, Gustilo RB. Infection after total hip arthroplasty: a study of the treatment of one hundred and six infections. J Bone Joint Surg [Am] 1996;78-A:512-23.

30. Gerhart TN, Roux RD, Horowitz G, et al. Antibiotic release from an experimental biodegradable bone cement. J Orthop Res 1988;6: 585-92.

31. Ascherl R, Stemberg A, Lechner F, Blumel G. Local treatment of infection with collagen gentamicin. Aktuelle Probl Chir Orthop 1990; 34:85-93. 